\title{
The urban cool island phenomenon in a high-rise high-density city and its mechanisms
}

Article

Accepted Version

Yang, X., Li, Y., Luo, Z. and Chan, P. W. (2017) The urban cool island phenomenon in a high-rise high-density city and its mechanisms. International Journal of Climatology, 37 (2). pp. 890-904. ISSN 0899-8418 doi:

https://doi.org/10.1002/joc.4747 Available at https://centaur.reading.ac.uk/60219/

It is advisable to refer to the publisher's version if you intend to cite from the work. See Guidance on citing.

To link to this article DOI: http://dx.doi.org/10.1002/joc. 4747

Publisher: John Wiley \& Sons

All outputs in CentAUR are protected by Intellectual Property Rights law, including copyright law. Copyright and IPR is retained by the creators or other copyright holders. Terms and conditions for use of this material are defined in the End User Agreement.

www.reading.ac.uk/centaur 
Central Archive at the University of Reading

Reading's research outputs online 
Manuscript revised for International Journal of Climatology, 2016

The Urban Cool Island Phenomenon in a High-Rise High-Density City and its Mechanisms

Xinyan Yang*1, Yuguo Li ${ }^{1}$, Zhiwen $\mathrm{Luo}^{2}$ and Pak Wai Chan ${ }^{3}$

${ }^{1}$ Department of Mechanical Engineering,

The University of Hong Kong,

Pokfulam Road,

Hong Kong SAR, China;

${ }^{2}$ School of the Built Environment,

The University of Reading,

Reading, United Kingdom.

${ }^{3}$ Hong Kong Observatory,

134A Nathan Road,

Kowloon, Hong Kong SAR, China

Word count of abstract: 243

Word count of text: 7,780

*Correspondence author:

Dr. Xinyan Yang, Department of Mechanical Engineering, The University of Hong Kong, Pokfulam Road, Hong Kong SAR, China.

Tel: (852) 6741 8146, Fax: (852) 2858 5415, Email: xinyan0915@gmail.com 


\section{The Urban Cool Island Phenomenon in a High-Rise High-Density City and its Mechanisms}

\section{ABSTRACT}

The urban heat island (UHI) phenomenon has been studied extensively, but there are relatively fewer reports on the so-called urban cool island (UCI) phenomenon. We reveal here that the UCI phenomenon exists in Hong Kong during the day, and is associated with the UHI at night under all wind and cloud conditions. The possible mechanisms for the UCI phenomenon in such a high-rise compact city have been discovered using a lumped urban air temperature model. A new concept of urban cool island degree hours (UCIdh) to measure the UCI intensity and duration is proposed. Our analyses reveal that when anthropogenic heat is small or absent, a high-rise and high-density city experiences a significant daytime UCI effect. This is explained by an intensified heat storage capacity and the reduced solar radiation gain of urban surfaces. However, if anthropogenic heat in the urban area increases further, the UCI phenomenon still exists, yet UCIdh decrease dramatically in a high-rise compact city. In a low-rise, low-density city, the UCI phenomenon also occurs when there is no anthropogenic heat, but easily disappears when there is little anthropogenic heat, and the UHI phenomenon dominates. This probably explains why the UHI phenomenon is often observed, but the UCI phenomenon is rarely observed. The co-existence of urban heat/cool island phenomena implies reduction of the daily temperature range (DTR) in such cities, and its dependence on urban morphology also implies that urban morphology can be used to control the urban thermal environment. 
Keywords: lumped urban air temperature model, urban cool island degree hours, urban heat island degree hours, urban morphology.

\section{INTRODUCTION}

The urban heat island (UHI) phenomenon has been extensively studied in the last decades, but there are fewer reports on the urban cool island (UCI) phenomenon, i.e. the air temperature of the surrounding rural area is warmer than that of the urban area. In contrast to the UHI, the UCI phenomenon always occurs during the day, and with relatively weak intensity (Kim and Baik, 2005; Johansson, 2006; Erell and Williamson, 2007; Memon et al., 2009). The reported causes of this phenomenon vary from city to city (Table 1). In fact, Luke Howard observed both the phenomenon of the UHI at night and that of the UCI during the day in London in 1833 (Landsberg, 1981). However, most studies since then have focused on the UHI. To some extent, urban air temperature reflects the impact of the urbanization process on the local climate. Here we study the UCI phenomenon in a high-rise compact city. Our aim is not to explain all the possible causes of the UCI phenomenon in different cities, but to understand why the urban cool and heat island phenomena co-exist at the same time in such cities.

Oke (1982) hypothesized a set of possible causes of energy balance changes in urban areas, which are categorized into four features, i.e. urban morphology, construction materials, building and traffic heat emissions and air pollution. Much effort has been put into developing multi-scale atmospheric modeling systems to consider the effect of all these parameters (Grimmond, et al., 2010; Masson, 2006), which require extensive computational time and modeling expertise. There is a need for simple yet insightful methods that do not 
need to be coupled to mesoscale atmospheric simulations, and which are capable of considering all of the factors which influence changes in the urban environment, in addition to having practical applications.

Silva et al. (2009) developed a zero-dimensional mesoscale model which simplifies the complex urban geometry as a unified entity and assumes one characteristic temperature to represent the entire urban fabric (both air and surfaces) while considering the energy balance. However, the model of Silva et al. (2009) computed the energy stored in the urban volume without distinguishing the urban air temperature from the urban surface temperature. It is also known that the urban surface temperature can be very different from that of urban air (Yang and Li, 2009). Modifications therefore needed to be introduced to reflect the difference between the two types of temperature, while retaining the simplicity of the model. Yam et al. (2002) developed a simple model for a naturally ventilated building, in which an effective thermal mass depth was adopted. Both the temperature of the contributing effective thermal mass and the indoor air is assumed to be uniform, but different, which has the advantage of the thermal mass materials not being in equilibrium with the indoor air. The approach can be easily extended to analysis of the urban thermal environment. This is essentially the same idea as the force-restore method (Deardorff, 1978 and Stull, 1988).

Based on the above two models, we developed an improved lumped mesoscale urban air temperature model for explaining the UCI phenomenon. The key idea is to develop characteristic temperatures that are representative of the urban air and urban surfaces, not the precise urban air temperature at a specific spatial point or location and the temperatures of each individual surface. The lumped model is limited in scope, but insightful, which will be 
shown later. It is not devoted to accurately predicting the urban cooling or warming intensity, but to improving our understanding of the impact of urban morphology on urban air temperature, particularly the co-existence of the urban heat and cool island phenomena.

\section{METHODOLOGIES}

\subsection{Lumped urban air temperature model}

For the idealized city-scale energy balance model, we simplify the complex urban geometry as a lumped system, and the force-restore method enables us to consider the average temperature of effective thermal mass and surfaces, $T_{s}$, to be the same throughout, while keeping the energy balance involved (Figure 1).

The two-dimensional urban plan area $A_{p}$ is separated into three surface types, i.e. vegetation, artificial ground areas (such as streets, highways, and playgrounds), and roofs:

$$
\begin{aligned}
& A_{v}+A_{a}+A_{r}=A_{p} \\
& f_{v}+f_{a}+f_{r}=1
\end{aligned}
$$

$A_{p}$ is the plan area. $A_{v}, A_{a}$ and $A_{r}$ are, respectively, the area of vegetated surfaces such as grass land and parks etc., man-made ground surfaces and roof surfaces, and the latter is equivalent to the building plan area. $f_{i}$ is the area fraction of each of the three urban surface types. In this study, the roof area fraction $f_{r}$ can be referred to as the plan area index $\lambda_{p}$. The complete surface area $A_{c}$ is assumed to be the sum of the urban plan area $A_{p}$ and the 
total building wall area $A_{w}$. Here we ignored the surface areas of other three-dimensional objects in a city.

$$
A_{c}=A_{w}+A_{p}=\left(1+f_{w}\right) A_{p}
$$

with the building wall surface ratio $f_{w}=A_{w} / A_{p}$. In a high-rise compact city, this ratio can be as high as 10 , as estimated for some high-rise compact areas such as Central in Hong Kong.

Since the lumped urban air temperature model is not coupled to the mesoscale atmospheric simulation, we adopted the model developed by Bueno et al. (2013) in order to access meteorological information above the urban canopy layer. The air temperature above the urban canopy layer $T_{u b l}$ can be calculated from the measurements at a rural weather station. Initially, the vertical diffusion model (VDM) was used to calculate the vertical profiles of potential temperatures of the rural site by solving a heat diffusion equation:

$$
\frac{\partial \theta(z)}{\partial t}=-\frac{1}{\rho(z)} \frac{\partial}{\partial z}\left[\rho(z) K_{d}(z) \frac{\partial \theta(z)}{\partial z}\right]
$$

where $z$ is the vertical height, $\rho$ is the air density. $K_{d}$ is the diffusion coefficient, which is related to the turbulent kinetic energy (TKE) at each vertical level: $K_{d}=C_{k} l_{k} E^{1 / 2}$ (Bougeault and Lacarrere, 1989), where $C_{k}$ is a numerical constant, $l_{k}$ is a characteristic length scale, and $E$ is the TKE, which is calculated based on Bueno et al. (2013). In order to define $l_{k}$, Bueno et al. (2013) applied complex formulations designed for boundary layer and mesoscale models (Therry and Lacarrere, 1982; Bougeault and Lacarrere, 1989). In this study, a more flexible and robust length scale formulation for the convective boundary layers has been 
adopted (Teixeira and Cheinet, 2003), where the length scale is directly linked with the square root of the turbulent kinetic energy, through a time scale $\tau: l_{k}=\tau \sqrt{E}$. Bueno et al. (2013) compared the VDM scheme with field data from the CAPITOUL experiment carried out in Toulouse, France on July 4, 2014. The vertical profiles of potential temperatures at 0400, 0800, 1300 and 1800 are presented. Our simplified VDM model was also evaluated against the same field data. The inputs are matched to those used by Bueno et al. (2013). The observation results at 0400 are used for the initial condition. Although estimation of the length scale is simplified, the results show good agreement with observations, and better than those of Bueno et al. (2013). The root-mean-square error ( $R M S E$ ) is reported here to quantify the absolute error between the model and observations. The RMSE for Bueno et al. (2013) and the simplified scheme is $1.53 \mathrm{~K}$ and $0.92 \mathrm{~K}$, respectively. Thus, the vertical profiles of potential temperatures can be well captured by the model.

After deriving the vertical profiles of potential temperatures of the rural site, a physically based urban boundary layer model was then used to calculate air temperature in the control volume delimited by the blending height and the urban boundary layer height. The thermal storage of the control volume equals the sum of the urban sensible heat flux and the advection heat flux. The energy balance is different for the daytime and nighttime urban boundary layer. Also, the difference lies between the advection effect driven by geostrophic wind and urban breeze circulation. For a comprehensive description of the model, please refer to Bueno et al (2013).

We define an urban control volume, which extends to the urban canopy layer height. We also consider the fact that the urban boundary layer can affect the surface. Thus, the advection 
heat flux has two components, from the rural site and from the urban boundary layer. The governing equation for the urban air energy balance is:

$$
\rho c_{p} q_{r u r}\left(T_{r u r}-T_{u}\right)+\rho c_{p} q_{u b l}\left(T_{u b l}-T_{u}\right)+h_{c} A_{t}\left(T_{s}-T_{u}\right)+Q_{a n t h r o} A_{p}=0
$$

$c_{p}$ is the specific heat of air. $Q_{a n t h r o}$ is the anthropogenic heat. $T_{r u r}, T_{u b l}$ and $T_{u}$ are the rural, urban boundary layer and canopy layer air temperature, respectively. The ventilation flow rate $q_{\text {rur }}$ and $q_{u b l}$ represents the volumetric flow rate being introduced into the urban area from the rural and urban boundary layers, respectively, which will be discussed in more detail in Section 2.2.

The energy balance equation for the idealized city surfaces becomes:

$$
m c \frac{d T_{s}}{d t}=A_{p}(1-\alpha) Q_{\text {sol }}-A_{a} Q_{\text {cond }, a}-A_{v} Q_{\text {cond }, v}-\left(U_{r} A_{r}+U_{w} A_{w}\right)\left(T_{s}-T_{\text {indoor }}\right)-A_{v} Q_{\text {evp }}-A_{c} Q_{\text {conv }}-A_{p} Q_{\text {rad }}
$$

The effective thermal mass of the urban area $m c$ can be expressed as the sum of the thermal mass of each surface $\sum \rho_{i} A_{i} \Delta x_{i} c_{i}$, where $\rho$ is the density and $c$ is the heat capacity. The effective depth $\Delta x$ is the depth into the ground or walls that can be reached by the diurnal temperature wave as used in the force-restore method (Deardorff, 1987). The first term on the right hand side is the solar radiation absorbed by the urban fabric, and $\alpha$ represents urban albedo. The second and the third terms are the conductive heat flux into horizontal artificial surfaces and vegetated surfaces. $Q_{c o n d, i}$ has the expression $k_{i} \frac{T_{s}-T_{s u b}}{\Delta x_{i}}$, where $k_{i}$ is the conductivity of each kind of surface, and $T_{\text {sub }}$ is the subsurface temperature at effective depth 
$\Delta x$, e.g. $T_{g r d}$ for vegetated and horizontal artificial subsurfaces. The fourth term is heat conduction into buildings. $U_{r}$ and $U_{w}$ are the $\mathrm{U}$ values of building roofs and walls, respectively. $T_{\text {indoor }}$ is the indoor air temperature. $Q_{\text {evp }}$ is the evapotranspiration heat flux from a natural vegetated surface, which can be estimated by the measured evapotranspiration for green areas $E_{t 0}$, the vegetated surface area $A_{v}$ and the physical properties of water. $E_{t 0}$ is assumed to be constant. $Q_{\text {conv }}$ is the convection heat transfer from the total urban surface. A flat plate forced convection relationship was adopted to simply estimate the convective heat transfer coefficient. The last term is the longwave radiation heat loss to the sky, the sky temperature of which is evaluated based on the urban air temperature and the dewpoint temperature. The impacts of these simplifications need to be evaluated in future using a more detailed simulation model. For more details of the terms $Q_{\text {evp }}, Q_{\text {conv }}$, and $Q_{\text {rad }}$, please refer to Silva et al. (2009).

\subsection{Air flow rate estimation}

An understanding of air mixing and transport within an urban area is necessary to define the air flow rate based on canopy geometric parameters and characteristics of the incident wind flow. Belcher et al. (2003) developed a quasi-linear canopy model to analyze the adjustment of the spatially averaged time-mean flow of a turbulent boundary layer within an urban canopy. When the flow passes through the urban area, the velocity decelerates substantially from the canopy drag. For continuity, the flow may be out of the canopy through the top vertically, and the turbulent stresses transport momentum downwards into the canopy. Eventually, a new balance forms, the removal of momentum by the drag of the canopy 
balancing the downward transport of momentum by turbulent stresses. This stage is referred to as the adjustment region with the length scale of $L_{c}$. The canopy drag length-scale $L_{c}$, which relates to the urban morphology, represents the length scale for the incident wind adjusted to the canopy, and the parameter $L_{c} / H$ determines the penetration depth of the winds into the canopy. Coceal and Belcher (2004) parameterized the canopy-element drag and expressed the $L_{c}$, which relates to the drag coefficient. For a low-rise urban area, the wind flows over and around the top of the buildings and the drag is small, while for the highrise urban area, most of the air flows only around buildings, which intensifies the drag. Cheng and Castro (2002) showed that the drag coefficient changes with height. For practicality, the drag coefficient takes 2 and 3 for low and tall buildings respectively. Thus,

for the low-rise urban area $L_{c}=\frac{\left(1-\lambda_{p}\right)}{\lambda_{f}} H$,

and for the high-rise urban area $L_{c}=\frac{2}{3} \frac{\left(1-\lambda_{p}\right)}{\lambda_{f}} H$,

where $\lambda_{f}$ and $\lambda_{p}$ are total frontal area per unit of ground area and total plan area per unit of ground area, respectively. $H$ is the plan area weighted-average building height.

Coceal and Belcher (2004) also showed that the wind within a uniform urban canopy adjusted after a distance $x_{0}=3 L_{c} \ln K$ based on the scaling arguments, motivated by a linear analysis of Belcher et al. (2003). The length-scale $x_{0}$ represents that at this point, the vertical transport driven by the mean velocity smoothly transits to that driven by the vertical transport by 
turbulence. The term $\ln K$ varies between 0.5 and 2 for typical urban parameters, and we take the value $\ln K=2$ in this analysis. The adjustment process is quite rapid with a spatial scale of a few hundred meters (Coceal and Belcher, 2005). Afterward, the downward transport of momentum by turbulent stresses begins to appear.

In order to estimate the amount of air flow rate by turbulence at the roof top of the canopy beyond the adjustment region, the model for the spatially averaged exchange velocity derived by Bentham and Britter (2003) is adopted here. It assumes two levels of momentum exchange. The first is the turbulent mixing process between the above-roof air and the in-canopy air. The second is the momentum lost by in-canopy air because of the drag around buildings. With further simplification, the model treats both the in-canopy and above-canopy velocity as constant, defined as $U_{C}$ and $U_{\text {ref }}$ while the exchange velocity between the flow is represented by $U_{E}$. $U_{C}$ can be estimated

for $\lambda_{f}>0.2, U_{C} / u^{*}=\left(2 / \lambda_{f}\right)^{1 / 2}$,

for $\lambda_{f}<0.2, U_{C} / u^{*}=\left(2 H / z_{0}\right)^{1 / 2}$

where $\lambda_{f}$ is the frontal area density. The constant above-canopy velocity $U_{r e f}$ is a velocity within the log-law region, thus it can be calculated. So after deriving the momentum flux balance equation, combined with the log-law wind velocity profile, the exchange rate can be obtained:

$$
\frac{U_{E}}{u^{*}}=\left[\frac{1}{\kappa} \ln \left(\frac{z_{r e f}-d}{z_{0}}\right)-\frac{U_{C}}{u^{*}}\right]^{-1}
$$


where $\kappa$ is the von Karman constant. The two length parameters, $d=0.7 H$ and $z_{0}=0.1 H$, are the zero-plane displacement height and roughness length respectively (Grimmond and Oke, 1999). As in Bentham and Britter (2003), a value of $z_{\text {ref }}=2.5 H$ is used.

The air flow rate for a control volume with a specified urban morphology can thus be estimated. In reality, the flow pattern in a high-rise, high-density city is much more complicated, and the concept of the wind flow and air exchange introduced above may no longer be appropriate for a high-rise compact city (Xie et al., 2006; Hang et al., 2011). But, for simplicity and also due to the lack of data, we apply the same calculation method of air flow rate in both low-rise and high-rise cities. We assume the air velocity from the rural site obeys the log law. $U$ is the velocity measured at height $z_{m}$ at the rural station, and $z_{0}$ is the roughness length. For the canopy layer with an area of $L \times L(7 \mathrm{~km} \times 7 \mathrm{~km}$ in this study) with regular building arrays, part of the incident wind flow is blocked by the buildings, and the block effect can be estimated as $\lambda_{p}^{1 / 2}$ based on the building geometries. The ventilation flow rate of the adjustment region $q_{\text {rur }}$ can be estimated as:

$$
q_{\text {rur }}=\int_{0}^{H}\left(1-\lambda_{p}^{1 / 2}\right) L U \frac{\ln \left(z / z_{0}\right)}{\ln \left(z_{m} / z_{0}\right)} d z
$$

The ventilation flow rate $q_{u b l}$ at the roof top of the canopy beyond the adjustment region is:

$$
q_{u b l}=\left[\left(L-x_{0}\right) L\right]\left(1-\lambda_{p}\right) U_{E}
$$

\subsection{A new measure of urban cool island intensity}


The urban heat island is mainly a nocturnal phenomenon. The intensity generally increases after sunset and reaches its maximum after three to five hours, and in the case of Figure 2, the urban-rural air temperature difference remains rather uniform at night. In theory, the intensity should decline slightly with time. In the existing UCI studies, the UCI intensity also refers to the urban-rural air temperature difference. However, examining the urban and rural air temperature profiles shown in Figure 2, we find that unlike UHI, UCI intensity changes significantly with time. It is difficult to quantify how cool the urban air is during the day. In fact, Winkler et al. (1981) showed the importance of the differences in observation times in defining the magnitude of the UHI. Using a single UHI/UCI intensity (magnitude) may not describe the urban heat/cool island phenomenon fully. A simple analysis as shown in the Appendix reveals that the difference may be due to the change of phase or the time of occurrence of the daily maximum temperature.

On the other hand, the so-called heat unit approach has often been used in related disciplines. The original attempt was in a study of plant-temperature relationships during the growing season (Wang, 1960). Engineers use the concept of heating and cooling degree hours to estimate the energy consumption of buildings (Santamouris and Assimakopoulos, 2013). In this study, we propose the use of the heat unit approach to analyze the accumulation of hourly UCI/UHI intensity over 24 hours. Since we are only interested in the diurnal cycle of air temperature, we use the unit of degree hours, which is the integration of urban and rural temperature differences over time. The UCI degree hours (UCIdh) can be represented by the area between the lower urban and higher rural air temperatures, and the UHI degree hours (UHIdh) by the area between the higher urban and lower rural air temperatures (Figure 2). If 
$\Delta T_{r-u}(t)$ is the temperature difference between the rural and urban air temperature, the UCIdh and the UHIdh of a day can be defined as:

$$
\begin{gathered}
\text { UCIdh }=\int_{\min \left(\Delta T_{r-u} \geq 0\right)}^{\max \left(\Delta T_{r-u} \geq 0\right)} \Delta T_{r-u}(t) d t \\
U H I d h=\int_{0}^{24}\left|\Delta T_{r-u}(t)\right| d t-\int_{\min \left(\Delta T_{r-u} \geq 0\right)}^{\max \left(\Delta T_{r-u} \geq 0\right)} \Delta T_{r-u}(t) d t
\end{gathered}
$$

Note that in this study, the analysis period is a day. The UCIdh and UHIdh refer to the daily UCI/UHI degree hours. Thus, the UCIdh and UHIdh reveal how much (in degrees) and for how long (in hours) the urban air temperature is lower/higher than the rural counterpart. This new measure offers a comprehensive measure of the UCI/UHI intensity, as both the difference in temperature and in duration are considered.

\subsection{The observed data in Hong Kong}

The target urban area for our study is the Kowloon Peninsula in Hong Kong $\left(47 \mathrm{~km}^{2} ; 22^{\circ} 15^{\prime} \mathrm{N}\right.$, $\left.114^{\circ} 15^{\prime} \mathrm{E}\right)$, with a high-rise and high-density morphology. Stewart and Oke (2012) developed the comprehensive approach of the Local Climate Zones (LCZ) classification, inherited from the urban climate zone scheme proposed by Oke (2004). The landscape universe is categorized by physical surface properties and anthropogenic heat flux. The 17 monitoring locations of the Hong Kong Observatory are classified using the LCZ system with a source area radius of $250 \mathrm{~m}$ (Siu and Hart, 2013). It concludes that the Hong Kong Observatory (HKO, $22^{\circ} 18^{\prime} \mathrm{N}, 114^{\circ} 10^{\prime} \mathrm{E}$, compact high-rise) is the best representative urban station, while

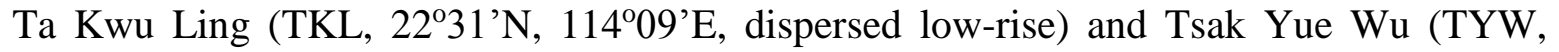
$22^{\circ} 24^{\prime} \mathrm{N}, 114^{\circ} 19^{\prime} \mathrm{E}$, forest) are the two representative rural stations. The distance between 
HKO/TKL and HKO/TYW is $25 \mathrm{~km}$ and $19 \mathrm{~km}$, respectively. The hourly air temperature data from 1988 to 2014 and from 1995 to 2014 was used for TKL/HKO stations and TYW/HKO station, respectively. The analysis proceeded by classifying the daily data in wind speed and cloud amount, and calculating the UCIdh and UHIdh for each category. In order to simplify the analysis without considering the evaporation difference between rural and urban area, we only considered the data for days with no precipitation, defined here as two days in a row with no precipitation. If more than eight hours of data were missing, then the day was excluded. The wind speed of the rural station was classified into two categories, less than or equal to $3 \mathrm{~m} / \mathrm{s}$ and greater than $3 \mathrm{~m} / \mathrm{s}$. The duration for each type had to be equal to or greater than 12 hours per day. The cloud cover of the urban station was classified into 5 groups, 0 Oktas (sky clear), 1-2 Oktas (fine), 3-5 Oktas (partly cloudy), 6-7 Oktas (cloudy) and 8 Oktas (overcast). The duration for each type had to be equal to or greater than 12 hours per day.

\section{RESULTS}

\subsection{The observed data in Hong Kong}

Because of the influence of building structures, the urban wind cannot represent the regional air flow (Morris et al., 2000). Also, cloud data is only available for the urban site (HKO). Thus, the wind speeds at the rural station and the cloud data from the urban station have been used for analysis. Figure 3 shows the seasonal frequency distributions for different rural wind (TKL) and urban area cloud (HKO) categories for the period 1988 to 2014. The distribution patterns based on the rural wind of TKL and TYW over the period studied are similar, and so we have only presented the pattern for the relevant wind speed categories from the TKL 
data. The wind speed of $3 \mathrm{~m} / \mathrm{s}$ is used to categorize the wind, since it is usually used as a criterion for classifying calm and windy days (Stull, 2000). The wind speed category $<=3 \mathrm{~m} / \mathrm{s}$ has the most observations, 3082 days in total. For both wind speed categories, summer has the least amount of days which satisfy the specified criteria, which is due to the large number of days with precipitation. On the other hand, winter has the greatest number of days satisfying the criteria. For both sites, more than half of the cloud events fell within 6-7 Oktas category, followed by the category of 1-2 Oktas, at around $20 \%$.

Figure 4 presents the influence of wind speed and cloud cover on UCIdh and UHIdh variation. Two notable features are that the city of Hong Kong exhibits the UCI phenomenon under all wind and cloud conditions. Compared to the UHIdh, which can range from 20 to nearly 100 ${ }^{\circ} \mathrm{C}$ hours, the value of the UCIdh is quite small, always close to or less than $10{ }^{\circ} \mathrm{C}$ hours. This illustrates that although UCIdh exist, the value is relatively small in a high-rise, high-density city. Overall, our data shows that calm and clear sky conditions result in the most developed UCI and UHI phenomena, and a decreasing magnitude of UCIdh and UHIdh is associated with increasing wind speed and cloud cover. However, increased cloud cover has more of an effect on the rate of decline of UHIdh than that of UCIdh. The inconsistency occurs when cloud cover is 8 Oktas, which may be due to the lack of samples as only about $2-3 \%$ of days meet the condition of no precipitation.

\subsection{Comparison of the modeled results and the observed data in Hong Kong}

The average hourly data from 1988 to 2014 of Ta Kwu Ling (TKL) and Hong Kong Observatory (HKO) during the summer (June - August) has been used for validation. A total of 116 calm (wind speed at the rural station was less than or equal to $3 \mathrm{~m} / \mathrm{s}$ ) and clear days 
(the cloud cover at the urban station was less than or equal to 2 Oktas) are selected. We only considered data for days with no precipitation, defined here as two days in a row with no precipitation. For prediction using our simple model, the fourth-order Runge-Kutta method is used to solve the ordinary differential equation (Equation 5 and 6) with the time step of 30s for the iteration. Table 2 lists the input parameters of the Kowloon Peninsula. The surface materials for the building wall, and building roof and horizontal artificial area are concrete and asphalt, respectively. The vegetated area is set as short grass growing on dry clay soil (40\% pore space). All material thermal properties are obtained from Oke (1987). The frontal area index, averaged over 4 wind directions over the whole Kowloon Peninsula is estimated to be 1.3 (Ng et al., 2011), and the ratio of building wall area to the plan area $f_{w}$ is estimated to be 5.2. We adopted the representative diurnal profiles of anthropogenic heat proposed by Sailor et al. (2015) with a maximum heat flux of $40 \mathrm{Wm}^{-2}$. In this study, we simply assume the friction velocity is $u^{*}=0.24$, which is also the value used in Hang (2009). For the predicted urban air temperature, the coefficient of determination $R^{2}$ (Grimmond et al., 2010) is found to be 0.997 and 0.994 respectively, by halving and doubling 0.24 . We conclude that the value of the friction velocity is not sensitive to this study. Our simple model predicts the main features of the daily temperature cycle well (Figure 5). The root-mean-square error ( RMSE ) and mean bias error ( $M B E$ ) are reported here to quantify bias and absolute error between the model and observations, respectively (Table 3). There are 2880 data points in total, and the $R M S E$ value is $0.39^{\circ} \mathrm{C}$. A discrepancy appears in the afternoon; our model postponed the occurrence of the daily maximum temperature about one hour. Also, the air temperature is overestimated such that the predicted temperature is higher than the observed 
data. In fact, we tested many other weather stations located in different parts of Hong Kong, and all of the air temperatures drop quickly in the afternoon. Sea breeze may be one of the reasons for the urban cooling effect.

Note that the aim of our model is not to precisely predict the urban air temperature. There are two unique aspects in the model; it is a lumped approach, and it predicts a kind of characteristic average air temperature, i.e., not at a particular point in time or space. On the other hand, the measured air temperature represents a single point in time. The comparison of such lumped model data with observed data at a single point is not entirely reasonable. However, the comparison clearly illustrates that such a simplified model is able to capture the major characteristics of the urban air temperature profile changes compared to the rural air temperature, including the decreased diurnal temperature range, increased mean air temperature. The simple model predicts all of these characteristics well. It is therefore suitable for use in studying the impact of different urban features on urban air temperature variations in term of trends and major characteristics. An additional merit of the model lies in its rapid calculation, and as such it could serve as an efficient tool to support policy making.

In the following paragraphs, a series of urban geometries are evaluated using our simple model, from a low-rise, low-density city to a high-rise, high-density city. To define the urban area fraction precisely, we assume the buildings are homogenously distributed. Table 4 illustrates the details of the urban morphology. Time constant $\tau$ is defined here, which can be expressed as $\tau=m c / \rho c_{p}\left(q_{r u r}+q_{u b l}\right)$. Time constants are a feature of the lumped system analysis for thermal systems, which can be defined and calculated when the temperature of objects remains uniform at all times during a heat transfer process. This parameter 
characterizes the response to the temperature variation of the environment temperature. A small value in time constant indicates that the object will approach the temperature of the environment in a short time. The response time of a city depends not only on thermal storage capacity but also on the air flow rate. Two urban areas with similar thermal storage capacity may introduce different air flow rates, and thus the ability to respond to the temperature change is different. The surface characteristics and environmental input data are the same as in Table 2. Yang and Li (2015) studied the impact of urban morphology on the average urban albedo, and a series of average urban albedos are calculated for the city of Hong Kong using the Model for Urban Surface Temperature in both summer and winter. In the current study, we use the averaged summer environmental input data as in Section 2.3. The urban albedo is a crucial value, but it is difficult to define. It is determined not only by the complexity of urban geometry but also by the albedo of the material, which is a function of the solar zenith angle and thus varies throughout the hour, day, and year. Yang and Li (2015) averaged the daily urban albedo, i.e. average urban albedo, in order to better understand the impact of canyon configuration on solar radiation absorption with minimal consideration of the time effect. They studied the effect of building density at constant building height on the average urban albedo, as well as the effect of the aspect ratio of the street on the urban albedo when the plan area index $\lambda_{p}$ is 0.44 (which represents $f_{r}=0.44$ in this study). We assume that the changing rate of the average urban albedo for the same plan area index with different aspect ratios is the same. Thus, the average urban albedo for all of the cases studied can be estimated.

\subsection{Effect of urban morphology under the condition of no anthropogenic heat}


Our study was first carried out under the condition of no anthropogenic heat $\left(Q_{a n t h r o}=0\right.$ $\mathrm{W} / \mathrm{m}^{2}$ ) for a city with an urban area of $7 \mathrm{~km} \times 7 \mathrm{~km}$. The size of the urban area affects the air flow rate. As mentioned above, the air flow rate is composed of the flow rate introduced from the rural area and urban boundary layer, and the former only affects the adjustment region with a spatial scale of a few hundred meters. The results do not depend on the size of the urban area if the length of the urban area is sufficiently larger than the adjustment region, when the air flow rate from turbulence at the roof top of the canopy dominates the total air flow rate. The predicted results of two extreme cases selected from Table 4, a low-rise, lowdensity city ( $\lambda_{p}=0.25, H / W=0.5$ and a high-rise, high-density city $\lambda_{p}=0.64$, $H / W=16)$ are compared in Figure 6, together with the corresponding rural temperature profile. The three profiles exhibit different characteristics. For all three profiles, there exists a morning warming period and an afternoon cooling period. But the warming and cooling rates are different for the three profiles. Both the warming and cooling rates are the lowest for the high-rise, high-density city due to thermal storage. The solar heat gain is stored during the day, leading to the lowest warming rate in the morning, and the stored heat is released at night, leading to the lowest cooling rate. Hence the high-rise, high-density city experiences a temperature cycle with a small daily temperature range. The situation for the low-rise, lowdensity city differs. The relatively small thermal storage allows its air temperature profile to follow that of the rural air closely. Although there is no anthropogenic heat, the urban albedo is smaller than the rural albedo, so the solar heat gain is greater in the city. There is also more thermal storage in the city than in the rural area due to the buildings and streets. This leads to a slightly slower warming rate in the morning, hence the urban air temperature is lower 
than the rural air in the morning. The greater solar heat gain also leads to a higher maximum air temperature in the low-rise, low-density city.

Examining Figure 6, we find that both cities experience a cooling island effect in the morning, and for the high-rise, high-density city, the phenomenon continues to the afternoon. The UCI intensity and duration is quite different for the two ideal cities. For the low-rise, low-density city, the UCIdh value is very small, only $5.4^{\circ} \mathrm{C}$ hours, while for the high-rise, high-density city, it is $27.1^{\circ} \mathrm{C}$ hours.

There are two explanations for the significant UCI phenomenon in the high-rise, high-density city:

The low solar radiation heat flux per total surface area. Solar radiation, which is related to the urban albedo, is the driving force behind the surface thermal flux process. In general, it decreases as the urban surface area increases. As estimated based on the method mentioned in Section 3.2, the urban albedo is 0.36 for the low-rise, low-density city, and 0.27 for the high-rise, high-density city, due to the intensified multi-reflection between urban surfaces. Although the latter absorbs more solar radiation, the air temperature is the lowest for most of the day, even lower than the incoming rural air temperature. This is because the surface temperature of the high-rise, high-density city is quite low. The underlying reason is related to the declination of the averaged solar radiation to the total surface area. The solar irradiation dramatically decreases as the total urban surface area increases The daily total solar radiation per total surface area is only $1.5 \times 10^{6} \mathrm{~J} / \mathrm{m}^{2}$ for the high-rise, high-density city compared to $1.0 \times 10^{7} \mathrm{~J} / \mathrm{m}^{2}$ for the low-rise, low-density city, since the former has a total urban area (including the wall surface area) approximately seven times larger than the latter. 
The large heat storage capacity. As mentioned previously, the time constant $\tau$ can be calculated as $\tau=m c / \rho c_{p}\left(q_{r u r}+q_{u b l}\right)$. Figure 7 demonstrates the relationship between the UCIdh and the time constant $\tau$. The results are derived from all the cases as shown in Table 4. Under the conditions of no anthropogenic heat, even the extremely low-rise and lowdensity city, which has a very small time constant $\tau$, will experience the UCI effect, although the UCIdh value is very small. As the time constant $\tau$ increases, the UCIdh are intensified for the same plan area index $\lambda_{p}$. For cities with the same time constant $\tau$, a denser city (larger plan area index $\lambda_{p}$ ) has a smaller UCIdh value. This can be explained by the fact that a denser city has a smaller air flow rate, which leads to a significant increase of the mean air temperature, while the changes of the phase and the amplitude are quite limited. Therefore, the UCIdh are dramatically reduced as urban density increases for the same time constant $\tau$. Figure 8 illustrates the relationship between UHIdh and the time constant $\tau$ based on all the cases listed in Table 4 . For the same plan area index $\lambda_{p}$ of the low-and medium-density city, the UHIdh first increase and then decrease as the time constant $\tau$ increases. One possible explanation is the varied air flow rate. As mentioned above, the air flow rate of the city has two components, the adjustment process and the turbulence at the roof top of the canopy. As the time constant $\tau$ increases, the air flow rate of the adjustment process always increases, while the turbulence-driven air flow rate at the roof top always declines. However, the rate of variation is quite different, which makes the overall air flow rate show as decreasing at first and then increasing. Therefore, the mean temperature first increases and then decreases, which leads to the same UHIdh trend, when the time constant $\tau$ increases. Also, in contrast to UCIdh for cities with the same time constant $\tau$, a denser city (with a larger plan area 
index $\lambda_{p}$ ) has a larger UHIdh value. The reason is that a smaller air flow rate for the denser city leads to an increase of the mean air temperature, thus UHIdh are increased.

\subsection{Effect of anthropogenic heat}

Anthropogenic heat (Ichinose, et al., 1999, Sailor and Fan, 2004, Sailor, 2011) can have a significant impact on urban air temperature. In the high-rise compact city of Hong Kong, transportation accounted for 32\% of all energy consumption in 2010 based on Hong Kong Energy End-use Data (EMSD, 2012). Buildings are the most important energy consumption category in Hong Kong, accounting for more than 60\% of energy use in 2010 (EMSD, 2012). Here, we only analyzed the impact of different levels of anthropogenic heat on urban air temperature under different types of urban geometry, without considering the impact of time and location. We still used the averaged summer environmental data of Hong Kong as input, and the diurnal variation profile of anthropogenic heat was assumed to be the same as proposed by Sailor et al (2015). The maximum anthropogenic heat increased from $0 \mathrm{~W} / \mathrm{m}^{2}$ to $200 \mathrm{~W} / \mathrm{m}^{2}$, at intervals of $50 \mathrm{~W} / \mathrm{m}^{2}$.

Figure 9 shows the relationship between the UCIdh for different levels of anthropogenic heat and the time constant $\tau$ with plan area index $\lambda_{p}=0.44$. When there is no anthropogenic heat, UCIdh are greater than zero for all situations considered. As the anthropogenic heat increases, the UCIdh dramatically decrease. For cities with a small time constant $\tau$, UCIdh easily reach zero as the anthropogenic heat increases, which means that under such conditions, the UCI phenomenon no longer occurs, and UHI phenomenon will dominate the entire day.

Figure 10 illustrates the relationship between the UCIdh for different plan area indices $\lambda_{p}$ 
and the time constant $\tau$ under the maximum anthropogenic heat of $40 \mathrm{~W} / \mathrm{m}^{2}$ condition. The tendency is similar to Figure 7 where there is no anthropogenic heat. But with the appearance of anthropogenic heat, UCIdh reach zero easily with a small time constant $\tau$ and the same plan area index $\lambda_{p}$.

\section{DISCUSSION}

\subsection{Why are there many UHI observations, but very few on UCI?}

In Figure 10, the UCIdh data for Hong Kong is included for reference. In order to eliminate the evapotranspiration effect, the vegetated surface is defined as an artificial surface in this case.

According to the measurement results, the city of Hong Kong experiences UCI during the day, which was also confirmed by Memon et al. (2009). Hong Kong is known as a high-rise, high-density city. In reality, most of the cities in the world are much less dense and have lower buildings than Hong Kong. The inset graph in Figure 10 illustrates the situations in which the thermal storage capacity $(m c)$ is less than or equal to the city of Hong Kong $\left(m c=1.8 \times 10^{14} \mathrm{~J} / \mathrm{K}\right)$. We can see that the UCIdh are quite small for most of the cities, and often zero. This may explain why previous studies primarily observed the UHI phenomenon, but only a few reported on the UCI phenomenon. Apart from the atmospheric conditions mentioned in Table 1, e.g., sea breeze, there are limited existing studies confirming our theory that the UCI phenomenon either occurs in cities with small thermal storage capacity and little anthropogenic heat, or cities with a high thermal storage capacity, even with a large amount of anthropogenic heat. Erell and Williamson (2007) conducted a field experiment in the city of Adelaide, Australia, which has a small heat capacity. The averaged aspect ratio $(H / W)$ 
of the studied urban canyon is only 1.35 . The anthropogenic heat within and from the surrounding area is quite low. The daytime urban cooling phenomenon was monitored for

nearly an entire year. Their observation data showed that compared to the UHI phenomenon, the intensity of UCI is low and its duration is short, i.e. the value of UCIdh is small. A compact city geometry is typically found in old city centers in hot dry regions, e.g. Fez in Morocco, which is known to be well-adapted to the climate (Johansson, 2006). The site survey data showed that in the old city of Fez, the aspect ratio is around 10, and there is no transportation, which leads to a pronounced UCI phenomenon all year around, but particularly in summer. The anthropogenic heat during the peak traffic time in the city of Beijing is quite high, over $200 \mathrm{~W} / \mathrm{m}^{2}$. Miao et al. (2008) observed the UCI phenomenon in Beijing for several hours from morning to noon in summer, and attributed the cause to the advection of warmer air to rural areas. We believe that apart from the environmental conditions of the atmosphere, the high density urban design in Beijing could also be one of the reasons.

\subsection{The implications of co-existence of daily UHI/UCI phenomena}

The observed data in Hong Kong as shown in Figure 2 and the modeling data shown in Figure 5 reveal the co-existence of UHI and UCI phenomena. This is very interesting from the urban climate control point of view. The co-existence of the two phenomena is equivalent to the reduction of the daily temperature range (DTR). The rural air temperature ranges from $24.0^{\circ} \mathrm{C}$ to $33.6^{\circ} \mathrm{C}$, while the urban air temperature ranges from $27.5^{\circ} \mathrm{C}$ to $32.1^{\circ} \mathrm{C}$, as shown by the observed data in Figure 2. We have learned from Figures 6 to 8, that urban morphology plays a dominant role in controlling the co-existence of the UHI and UCI phenomena. This suggests 
that urban morphology can be used to control the urban air temperature. Urban morphology affects the urban albedo, wind penetration, and thermal storage and heat distribution. Clearly, the relationship between urban morphology and anthropogenic heat is complex, and beyond the scope of this study. Our results call for attention to be paid to urban morphology design in terms of urban climate control.

\subsection{Limitations of the present study}

Our model is very simple, and is not capable of considering the impact of atmospheric conditions such as sea breeze and cold fronts, which are known to drive the UCI phenomenon. But our model clearly reveals the essential urban air temperature characteristics, as discussed in Section 3.1. The impact of urban morphology on the daily temperature cycles, as presented in the Results, lacks supporting field data. As discussed, the results are plausible, and supported by existing observations, but further field data collection will be needed. Our work reveals the necessity and importance of providing supplementary morphology data when urban heat/cool island phenomena are observed and reported.

\section{CONCLUSIONS}

We reported and explained the existence of the UCI phenomenon in Hong Kong, a high-rise compact city. A lumped model for estimating the urban air temperature was developed. Compared with averaged summer observation data from Hong Kong over a period of fifteen years, the model is able to capture the important features of the diurnal urban air temperature profile, including the daytime cool island phenomenon. A new measure of urban heat/cool island intensity is suggested, i.e. UHI degree hours and UCI degree hours. Different urban geometry, from a low-rise, low-density city to a high-rise, high-density city were studied to 
understand the influence of urban geometry on the urban air temperature at different anthropogenic heat levels.

Under the condition of no or low anthropogenic heat emissions, a high-rise, high-density city experiences more UCIdh than a low-rise, low-density city. This can be explained by the relatively small amounts of solar radiation received by every urban surface in a high-rise, high-density city, with a high heat storage capacity. Both of these factors lead to a limited urban surface temperature increase during the day. Thus, the UCI phenomenon for a highrise, high-density city is significant.

As anthropogenic heat increases, UCIdh still exist yet dramatically reduce in a high-rise, high-density city. For most world cities with a lower rise and lower density, the UCI phenomenon disappears and the UHI phenomenon dominates the entire day according to our modeling study, which confirms the observations from some previous studies. Our study shows that the UCI phenomenon only occurs in low-rise, low density cities with little anthropogenic heat, or in high-rise, high-density cities even with large amounts of anthropogenic heat.

\section{ACKNOWLEDGEMENTS}

We want to thank Mr. Kai Wang, who shared his knowledge and provided valuable input. This study was financially supported by the Research Grants Council Collaborative Research Fund Scheme (HKU9/CRF/12G) of Hong Kong. We sincerely acknowledge two anonymous reviewers for their very constructive and useful comments. 


\section{REFERENCES}

Belcher SE, Jerram N, Hunt JCR. 2003. Adjustment of a turbulent boundary layer to a canopy of roughness elements. Journal of Fluid Mechanics 488: 369-398.

Bentham T, Britter R. 2003. Spatially averaged flow within obstacle arrays. Atmospheric Environment 37: 2037-2043.

Bohnenstengel SI, Evans S, Clark PA, Belcher SE. 2011. Simulations of the London urban heat island. Quarterly Journal of the Royal Meteorological Society 137: 1625-1640.

Bougeault P, Lacarrére P. 1989. Parameterization of orography-induced turbulence in a mesobeta-scale model. Monthly Weather Review 117: 1872-1890.

Bueno B, Hidalgo J, Pigeon G, Norford L, Masson V. 2013. Calculation of air temperatures above the urban canopy layer from measurements at a rural operational weather station. Journal of Applied Meteorology and Climatology 52: 472-483.

Cheng H, Castro IP. 2002. Near wall flow over urban-like roughness. Boundary-Layer Meteorology 104: 229-259.

Coceal O, Belcher SE. 2004. A canopy model of mean winds through urban areas. Quarterly Journal of the Royal Meteorological Society 130: 1349-1372.

Coceal O, Belcher SE. 2005. Mean winds through an inhomogeneous urban canopy. Boundary-Layer Meteorology 115: 47-68. 
Deardorff JW. 1978. Efficient prediction of ground surface temperature and moisture, with inclusion of a layer of vegetation. Journal of Geophysical Research 83: 1889-1903.

Electrical and Mechanical Services Department: 2012. Hong Kong Energy End-use data 2012. from http://www.emsd.gov.hk/emsd/eng/pee/edata.shtml. Accessed in May 2013.

Erell E, Williamson T. 2007. Intra-urban differences in canopy layer air temperature at a mid-latitude city. International Journal of Climatology 27: 1243-1255.

Gedzelman SD, Austin S, Cermak R, Stefano N, Partridge S, Quesenberry S, Robinson DA. 2003. Mesoscale aspects of the urban heat island around New York City. Theoretical Applied Climatology 75: 29-42.

Grimmond CSB, Blackett M, Best MJ, Barlow J, Baik JJ, Belcher SE, Bohnenstengel SI, Calmet I, Chen F, Dandou A, Fortuniak K, Gouvea ML, Hamdi R, Hendry M, Kawai T, Kawamoto Y, Kondo H, Krayenhoff ES, Lee SH, Loridan T, Martilli A, Masson V, Miao S, Oleson K, Pigeon G, Porson A, Ryu YH, Salamanca F, Shashua-Bar L, Steeneveld GJ, Trombou M, Voogt J, Young D, Zhang N. 2010. The international urban energy balance models comparison project: first results from phase 1. Journal of Applied Meteorology and Climatology 49: 1268-1292.

Grimmond CSB, Oke TT. 1999. Aerodynamic properties of urban areas derived from analysis of surface form. Journal of Applied Meteorology 38: 1262-1292.

Hafner J, Kidder SQ. 1999. Urban heat island modeling in conjunction with satellitederived surface/soil parameters. Journal of Applied Meteorology 38: 448-465. 
Hang J. 2009. Wind conditions and urban ventilation in idealized city models. PhD thesis, The University of Hong Kong, Hong Kong, 365pp.

Hang J, Li Y, Sandberg M. 2011. Experimental and numerical studies of flows through and within high-rise building arrays and their link to ventilation strategy. Journal of Wind Engineering and Industrial Aerodynamics 99: 1036-1055.

Ichinose T, Shimodozono K, Hanaki K. 1999. Impact of anthropogenic heat on urban climate in Tokyo. Atmospheric Environment 33: 3897-3909.

Jim CY. 2002. Planning strategies to overcome constraints on greenspace provision in urban Hong Kong. Town Planning Review 73(2): 127-152.

Johansson E. 2006. Influence of urban geometry on outdoor thermal comfort in a hot dry climate: A study in Fez, Morocco. Building and Environment 41: 1326-1338.

Kim YH, Baik JJ. 2005. Spatial and temporal structure of the urban heat island in Seoul. Journal of Applied Meteorology 44: 591-605.

Landsberg HE. 1981, The Urban Climate, Academic Press, New York, 275pp.

Masson V. 2006. Urban surface modeling and the meso-scale impact of cities. Theoretical Applied Climatology 84: 35-45.

Morris CJG, Simmonds I. 2000. Associations between varying magnitudes of the urban heat island and the synoptic climatology in Melbourne, Australia. International Journal of Climatology 20: 1931-1954. 
Memon RA, Leung DYC, Liu C. 2009. An investigation of Urban Heat Island Intensity (UHII) as an indicator of urban heating. Atmospheric Research 94: 491-500.

Miao S, Chen F, Lemone MA, Tewari M, Li Q, Wang Y. 2009. An observational and modeling study of characteristics of urban heat island and boundary layer structures in Beijing. Journal of Applied Meteorology and Climatology 48: 484-501.

Ng E, Yuan C, Chen L, Ren C, Fung JCH. 2011. Improving the wind environment in highdensity cities by understanding urban morphology and surface roughness: a study in Hong Kong. Landscape and Urban Planning 101: 59-74.

Oke TR. 1982. The energetic basis of the urban heat island. Quarterly Journal of the Royal Meteorological Society 108: 1-24.

Oke TR. 1987, Boundary Layer Climates, 2nd edn, Routledge: London \& New York. $435 \mathrm{pp}$.

Oke TR. 2004. Initial guidance to obtain representative meteorological observations at urban sites. IOM Rep. 81, WMO/TD-No. 1250, 47 pp.

Sailor DJ, Fan H. 2004. The importance of including anthropogenic heating in mesoscale modeling of the urban heat island. 84th annual meeting of the AMS, Symposium on Planning, Nowcasting, and Forecasting in the Urban Zone, Seattle.

Sailor DJ. 2011. A review of methods for estimating anthropogenic heat and moisture emissions in the urban environment. International Journal of Climatology 31: 189199. 
Sailor DJ, Georgescu M, Milne JM, Hart MA. 2015. Development of a national anthropogenic heating database with an extrapolation for international cities. Atmospheric Environment 118: 7-18.

Santamouris M, Assimakopoulos D. (Eds.): 2013, Passive Cooling of Buildings, James and James: London. 468pp.

Silva HR, Bhardwaj R, Phelan PE. Golden JS, Grossman-Clarke S. 2009. Development of a zero-dimensional mesoscale thermal model for urban climate. Journal of Applied Meteorology and Climatology 48: 657-668.

Siu LW, Hart MA. 2013. Quantifying urban heat island intensity in Hong Kong SAR, China. Environmental monitoring and assessment 185: 4383-4398.

Steinecke K. 1999. Urban climatological studies in the Reykjavík subarctic environment, Iceland. Atmospheric Environment 33: 4157-4162.

Stewart ID, Oke TR. Local climate zones for urban temperature studies. Bulletin of the American Meteorological Society 93: 1879-1900.

Stull, R. B. 1988. An Introduction to Boundary Layer meteorology. Kluwer Academic Publishers, Dordrecht, the Netherlands, 669pp.

Teixeira J, Cheinet S. 2003. A simple mixing length formulation for the eddy-diffusivity parameterization of dry convection. Boundary-Layer Meteorology 110: 435-453.

Therry G, Lacarrère P. 1982. Improving the eddy kinetic energy model for planetary boundary layer description. Boundary-Layer Meteorology 25: 63-88. 
Wang JY. 1960. A critique of the heat unit approach to plant response studies. Ecology, 41(4): 785-790.

Winkler JA, Skaggs RH. 1981. Temperature adjustments on the Mineapolis-St. Paul urban heat island. Journal of Applied Meteorology 20: 1295-1300.

Wong MS, Nichol J, Ng E. 2011. A study of the "wall effect" caused by proliferation of high-rise buildings using GIS techniques. Landscape and Urban Planning 102: 245253.

Xie XM, Huang Z, Wang J. 2006. The impact of urban street layout on local atmospheric environment. Building and Environment 41: 1352-1363.

Yam J, Li Y, Zhen Z. 2002. Nonlinear coupling between thermal mass and natural ventilation in buildings. International Journal of Heat and Mass Transfer 46: 12511264.

Yang L, Lam JC, Tsang CL. 2008. Energy performance of building envelopes in different climate zones in China. Applied Energy 85: 800-817.

Yang L, and Li Y. 2009. City ventilation of Hong Kong at no-wind conditions. Atmospheric Environment 43: 3111-3121.

Yang X, and Li Y. 2015. The impact of building density and building height heterogeneity on average urban albedo and street surface temperature. Building and Environment 90: $146-156$. 


\section{APPENDIX A - Comparison of two sinusoidal curves as ideal urban/rural air temperature profiles}

To illustrate the difficulties of using the traditional "urban heat/cool island intensity" when there is a phase difference between urban and rural air temperatures, we consider two sinusoidal curves. An ideal rural air temperature profile is defined as:

$$
T_{\text {rural }}=\frac{1}{2}+\frac{1}{2} \sin \left(\frac{\pi}{12} t-\frac{3}{4} \pi\right)
$$

The exact values of the mean, the amplitude and the phase are not important here. There is a corresponding urban air temperature profile. In theory, compared to the rural air temperature profile, the ideal urban air temperature profile is represented by combined changes in the mean, the amplitude and the phase. To illustrate the differences, we consider each change separately, i.e. phase delay, mean temperature increase, and amplitude reduction.

a) Phase delay and phase advance

Unlike building interiors, urban environments experience heating and cooling due to different mechanisms. Solar radiation is the most important. It is the heat source of the Earth-atmosphere system, and it is the trigger for all of the other heat transfer mechanisms. The radiation heat flux first affects the thermal mass temperature of the urban area and further influences the urban air temperature due to convection.

Due to thermal storage of the urban area, the timing of the peak temperatures can be different from the rural area. A phase delay alone leads to differences between 
urban and rural air temperature, though the mean and amplitude remain unchanged, as shown in Figure A1(a). Figure 2 shows that there is a phase delay for the urban air temperature in Hong Kong from its rural counterpart during clear and calm days. In Figure A1(b), a linear relationship between the phase shift and the normalized UCIdh and UHIdh are revealed. When the phase shift increases, both the duration and intensity of the UCI and UHI are increased, hence both UCIdh and UHIdh increase. As the mean is the same for both the rural and urban air temperatures, UCIdh and UHIdh remain equal as the phase changes. They are not equal to zero due to the phase difference alone. For the situation with a phase change alone, it is difficult to define the UHI intensity or UCI intensity (urban air temperature minus rural air temperature at any time). At any time of the day, we can define this intensity, but such a parameter does not reveal much.

b) Mean temperature increase

It is very unlikely that the urban mean temperature is less than the rural mean. Hence we only consider the situation of an increase in mean temperature. We keep the amplitude and phase of the urban air temperature the same as the rural air. Assuming the mean temperature changes from 0.5 to 0.9 ; see Figure A2 (a). Figure A2 (b) shows the relationship between the normalized mean temperature and the normalized UCIdh and UHIdh. As the mean temperature increases, the UCI phenomenon is absent, which means that UCIdh value is zero. But we could say that the urban heat island phenomenon exists all the time, and the UHIdh always increase as the mean increases. For this situation with the change in mean alone, the traditional urban heat island intensity can be easily defined. 
c) Amplitude reduction

It is generally observed that the daily temperature range (DTR) is smaller in a city than in the surrounding areas. Here we consider that the urban amplitude is reduced from the rural amplitude of 0.5 to 0.1 ; see Figure A3 (a), while maintaining the urban phase and the mean the same as the rural values. As the urban and rural means are equal, the UCIdh and UHIdh are equal under all conditions, and both increase as amplitude decreases. The duration of both the UCI and the UHI phenomena is the same.

Based on the above analysis, the following observations are made. The UCIdh and UHIdh are equal with the change in phase or the amplitude, but differ when the mean is changed. The traditional definition of the urban heat island intensity can work well when the urban/rural difference is caused by the change in the mean or amplitude. However, it does not work well when there is a change in phase. A phase change alone does not actually lead to any 'quantitative' change in the temperature profile, and the only difference is that the high or low point occurs at different times in the urban and rural profiles. In such a situation, it seems that the concepts of UCIdh and UHIdh may be more revealing. 